Article

\title{
Investigation of Thick-Film-Paste Rheology and Film Material for Pattern Transfer Printing (PTP) Technology
}

\author{
Adrian Adrian ${ }^{1} \oplus$, Dominik Rudolph ${ }^{1}$, Jan Lossen ${ }^{1} \oplus$ and Norbert Willenbacher ${ }^{2, *}$ \\ 1 International Solar Energy Research Center (ISC) Konstanz e.V., D-78467 Konstanz, Germany; \\ adrian@isc-konstanz.de (A.A.); dominik.rudolph@isc-konstanz.de (D.R.); jan.lossen@isc-konstanz.de (J.L.) \\ 2 Applied Mechanics Group, Institute for Mechanical Process Engineering and Mechanics, Department of \\ Chemical Engineering, Karlsruhe Institute of Technology, D-76131 Karlsruhe, Germany \\ * Correspondence: norbert.willenbacher@kit.edu
}

Citation: Adrian, A.; Rudolph, D.; Lossen, J.; Willenbacher, $\mathrm{N}$. Investigation of Thick-Film-Paste Rheology and Film Material for Pattern Transfer Printing (PTP)

Technology. Coatings 2021, 11, 108. https://doi.org/10.3390/coatings 11010108

Received: 30 December 2020

Accepted: 13 January 2021

Published: 19 January 2021

Publisher's Note: MDPI stays neutral with regard to jurisdictional claims in published maps and institutional affiliations.

Copyright: (c) 2021 by the authors. Licensee MDPI, Basel, Switzerland. This article is an open access article distributed under the terms and conditions of the Creative Commons Attribution (CC BY) license (https:// creativecommons.org/licenses/by/ $4.0 /)$.

\begin{abstract}
Steady cost pressure in silicon solar cell production leads to a continuous reduction of silver consumption per cell. Pattern Transfer Printing (PTP) technology enables to reduce silver consumption by depositing smaller front electrodes on solar cells. Here, we aim at a better understanding of the laser deposition process. The aspect ratio of printed lines improved with increasing paste yield stress but was lower than the theoretical aspect ratio for a given trench geometry, suggesting that line spreading was caused by the pressure that was due to the vaporization of volatile paste components and a yield stress reduction that was due to local paste heating. A low laser power threshold, mandatory to fabricate narrow electrodes with a high aspect ratio and low amount of debris, could be achieved using pastes with low boiling temperature of volatile components and poor wetting between paste and film. The material with the lowest light transmission exhibited the lowest laser power threshold. We attribute this to the weaker adhesion to the paste and a better alignment with the laser focal plane. Our results provide valuable guidelines for paste and film material design aimed at narrower electrodes, with a higher aspect ratio to be obtained at an even lower laser power threshold in PTP-based solar cell metallization.
\end{abstract}

Keywords: PTP; laser printing; metallization; solar cell; silver paste

\section{Introduction}

In the last few decades, renewable energies have become more attractive worldwide, especially photovoltaics (PV) [1]. The average annual growth rate of global electricity production from PV was 33.1\% between 1990 and 2019, and it was even higher than from wind energy at $20.4 \%$ [2]. Constant improvement of cell and module efficiency, as well as price reduction, contributed significantly to the tremendous growth of PV. Curbing silver consumption in cell fabrication is particularly demanded, since silver is the costliest non-silicon material in the value chain of crystalline silicon solar cell fabrication. Therefore, PV industries continue to reduce electrode (contact finger) width further, not only to lessen the fabrication cost but also to improve the cell efficiency that is due to less shading on the front-side. Using standard industrial screen-printing technology, an electrode width of $53 \mu \mathrm{m}$ was achieved in 2015 and was decreased further to $36 \mu \mathrm{m}$ in 2019 [3]. At the research level, the width of electrodes obtained by screen-printing was $22 \mu \mathrm{m}$ in 2019 [4] and $19 \mu \mathrm{m}$ in 2020 [5]. Despite the promising results at the research level, an industry PV roadmap forecast that around ten years are required to reduce silver paste consumption by $50 \%$ with an electrode width of $20 \mu \mathrm{m}$ at the industrial level [3].

As an alternative technology to screen-printing, Pattern Transfer Printing (PTP) technology has shown its potential to print narrow electrodes with a high aspect ratio [6-8]. We demonstrated that PTP could fabricate electrodes with an average width of $18 \mu \mathrm{m}$, but the highest cell efficiency for a six busbars structure was obtained with a finger width of $22 \mu \mathrm{m}$ [8]. For front-side metallization, a trade-off between optical and electrical losses on 
solar cell performance is necessary. On the one hand, a solar cell with narrower electrodes generates a higher current, due to less shading on the front-side. On the other hand, thin electrodes lead to a decrease in fill factor (FF), due to the rising contribution of contact resistance and lateral grid resistance to the total series resistance. Optimizing the number of electrodes as well as increasing the number of busbars are two possible ways to minimize the $F F$ loss and at the same time maximize the full potential of narrow electrodes.

The printing sequence of PTP consists of two steps; the filling process and transfer process (see Figure 1). A transparent polymer film with embossed trenches is rolled to the filling position, where two metal squeegee blades with different inclinations fill paste into the trenches. The first squeegee fills the paste into the trenches, but due to the inclination of $60^{\circ}$ toward the film surface, part of the paste is scooped away creating a concave paste surface in the trenches. The second squeegee blade with an inclination of $130^{\circ}$ fills this remaining volume with paste and concurrently removes the surplus of paste from the film surface. Then, the film with filled trenches is rotated $180^{\circ}$ and moved to the printing position. Simultaneously, a substrate is mounted on a moving chuck and positioned underneath the film at a distance of $200 \mu \mathrm{m}$. One after the other, the trenches are irradiated by a laser with a wavelength of $1070 \mathrm{~nm}$. The laser irradiance is transmitted through the transparent film and its energy is absorbed first by the paste surface. The resulting heat energy vaporizes the organic component in the interface region between the paste and trench and forms a high-pressure vapor layer at the paste/film interface. When sufficient pressure is built up at the paste/film interface, the paste is released onto the substrate surface.

(a) Filling process

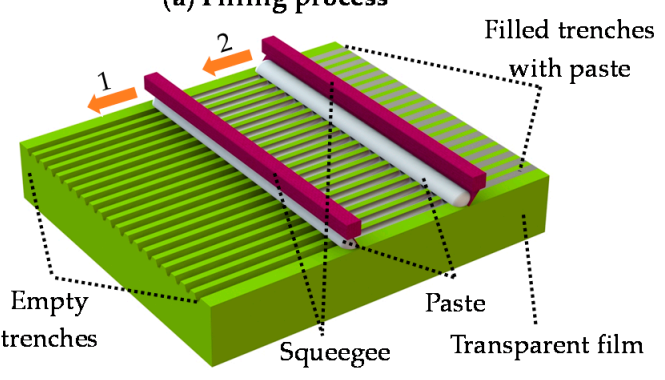

(b) Transfer process

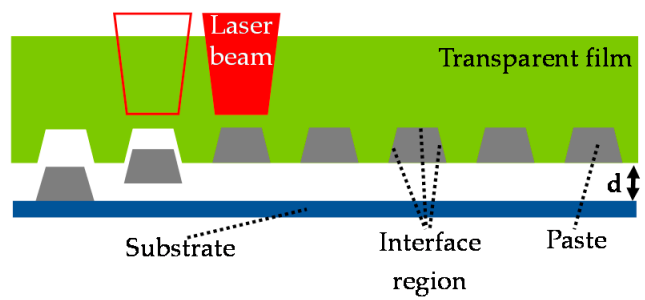

Figure 1. Illustration of the printing sequence of Pattern Transfer Printing (PTP): (a) filling process; (b) transfer process. Reprinted, with permission, from ref [8]. ( [2020] IEEE.

The paste transfer process of PTP gradually changes with increasing laser power. We discuss exemplarily three cases of this process related to different laser powers (see Figure 2). First, the operating laser power is too low to generate pressure at the paste/film interface sufficient to overcome the adhesive strength between the polymer film and paste. The paste cannot be transferred and stays inside the trenches. Next, optimum transfer is observed when the operating laser power is just high enough to generate a pressure in the interface region sufficient to overcome the adhesion between paste and polymer film. Thus, the paste is released onto the substrate underneath and the printed lines have an optimum geometry with only slight traces of splashing. Splashing happens when the generated pressure overcomes the cohesion force of the paste and removes a small fraction of particles from the paste's main body. These particles, called debris, can be found later scattered around printed electrodes. In the third case, we call it explosive transfer. The applied laser power is notably higher than in the previous case, exceeding the adhesive strength by far and therefore releases the paste completely. The excess pressure will not only overcome the cohesion strength to remove a considerable amount of particles from the main body but also accelerate the ejected paste onto the surface and deform it towards a broader line width. 
(a)



$\uparrow \mathrm{d}$


(b)
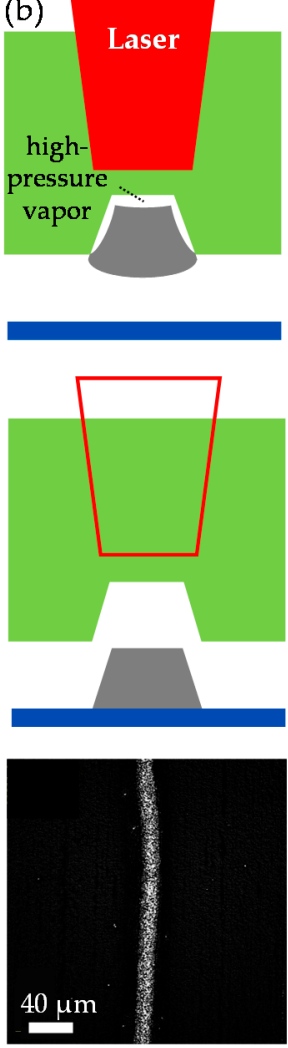

(c)
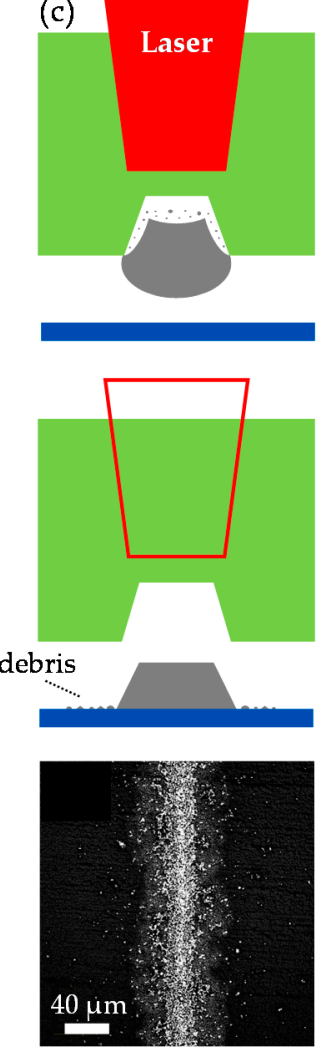

Figure 2. Schematic of paste transfer during the PTP laser transfer process for different laser power: (a) no transfer, when the operating laser is below the laser power threshold; (b) optimum transfer, for laser power slightly above the threshold; (c) explosive transfer, when the laser power is significantly above the laser power threshold.

PV industries have strict requirements for the number of allowed interruptions per finger line $[9,10]$. Although it might not be the technical optimum, electrodes without any interruptions are prioritized over a slightly better line geometry. Hence, in this study, we describe the laser power threshold as the required laser power to transfer the paste from entire trenches completely without any interruption for the whole area of a solar cell. The geometry of printed electrodes depends on the laser power; the higher the laser power, the lower the aspect ratio of the electrodes [8]. A slightly higher laser power than the threshold of optimum transfer is mostly utilized to avoid interruptions that are due to laser inhomogeneity. However, a higher laser power creates a certain amount of debris around the paste's main body and sacrifices the best aspect ratio of printed electrodes.

Previous publications showed the advantage of PTP-based electrodes compared to the industrial standard screen-printing technology in reducing the silver consumption substantially and simultaneously increasing the cell efficiency [6-8]. In this work, we focus on two key aspects that control the PTP laser transfer process from a materials point of view, namely the physico-chemical properties of the used silver paste and the film material. We discuss how paste rheology affects the spreading of the transferred paste and hence the aspect ratio of the printed finger lines. Furthermore, we exhibit how the laser power threshold is affected by the boiling point of the used paste as well as by the adhesion between paste and film material. The study provides guidelines on how narrow electrodes with a high aspect ratio can be achieved through the careful adaption of paste and film properties. 


\section{Materials}

\subsection{Silver Paste}

For this paper, we fabricated electrodes using six different silver pastes, specially modified for PTP technology from paste supplier Heraeus Precious Materials. The solid content of silver and glass particles, the organic vehicle content, and viscosity of each paste as analyzed by the supplier are given in Table 1 . The viscosity values were measured using a viscometer and a cone plate spindle CPE-51 (Brookfield Engineering Laboratories, Inc., Middleboro, MA, USA) at $1 \mathrm{rpm}$ and $25{ }^{\circ} \mathrm{C}$ for $5 \mathrm{~min}$.

Table 1. Components and specifications of six silver pastes modified for Pattern Transfer Printing (PTP) application.

\begin{tabular}{cccc}
\hline Paste & Solids [wt.\%] & Organic Vehicle ${ }^{\mathbf{1}}$ [wt.\%] & Viscosity [Pa·s] \\
\hline A & 90.74 & 9.26 & 55.9 \\
B & 91.21 & 8.79 & 247 \\
C & 89.00 & 11.00 & 186 \\
D & 90.95 & 9.05 & 186 \\
E & 90.66 & 9.34 & 150 \\
F & 91.14 & 8.86 & 143
\end{tabular}

${ }^{1}$ The organic vehicle might be a mixture of solvent, thickener, thixotropic agent, surfactant, plasticizer, and other additives. The actual constituents for each paste and their proportion of organic vehicle are held confidentially by the manufacturer.

\subsection{Transparent Film}

Two newly developed films (M1 and M2) and one standard film (M3) were supplied by Utilight Ltd. (Yavne, Israel) and used to investigate the influence of film material on laser power during the transfer process (see Table 2). Each transparent film was embossed with three different trench geometries using a rigid patterned metal (see Figure 3).

Table 2. Three different film materials were used in this study.

\begin{tabular}{ccc}
\hline Transparent Film & Film Thickness $[\mu \mathrm{m}]$ & Material \\
\hline M1 & 80 & Polyethylene (PE) \\
M2 & 150 & Polyvinyl chloride (PVC) \\
M3 & 200 & Amorphous polyethylene terephthalate (APET) \\
\hline
\end{tabular}

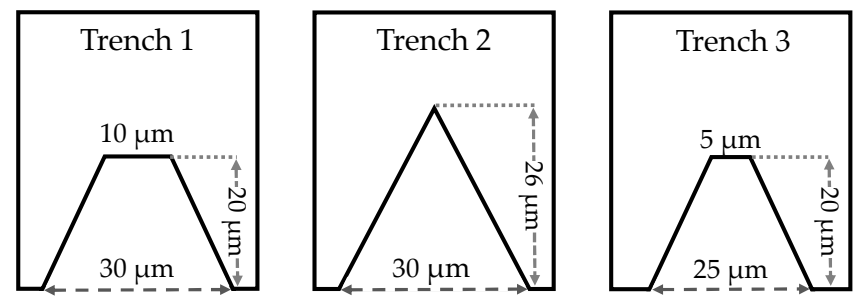

Figure 3. Three different trench shapes for this study and its geometry.

\section{Experimental Methods}

\subsection{Rheological Measurement}

The yield stress defines the minimum shear stress that must be applied to induce the transition from elastic solid-like behavior to viscous liquid-like behavior [11]. Yield stress measurements were performed at $20^{\circ} \mathrm{C}$ using a rotational rheometer Rheostress 150 (Thermo Fisher Scientific, Karlsruhe, Germany) equipped with a vane geometry. The shear stress was stepwise increased from 1-3500 Pa. The yield stress for each paste was determined from logarithmic plots of deformation versus shear stress using the tangent intersection point method [12]. Experiments were performed in triplicate always using a fresh sample. 


\subsection{Thermal Behavior Analysis of Silver Pastes}

Laser irradiation evaporates the solvent of a silver paste at the paste/film interface. We used differential scanning calorimetry (DSC), a common method for characterizing the thermal properties of materials, to determine the boiling point of the liquid phase of the pastes. $100 \mathrm{mg}$ of paste was filled into a standard crucible made of aluminum and sealed with a pierced alumina lid. The crucible with a sample was arranged side to side with a reference crucible inside a DSC 214 Polyma (Netzsch-Gerätebau GmbH, Selb, Germany). Both crucibles were heated with $20 \mathrm{~K} \cdot \mathrm{min}^{-1}$ at a dynamic $\mathrm{N}_{2}$ atmosphere of $40 \mathrm{~mL} \cdot \mathrm{min}^{-1}$. By analyzing heat flow as a function of temperature, the thermal behavior of pastes $\mathrm{E}$ and F were analyzed and compared. For both pastes, measurements were repeated three times.

\subsection{Tensiometry}

The organic vehicle of the silver pastes determines the wetting of the transparent film material. Therefore, the organic vehicle of pastes $\mathrm{E}$ and $\mathrm{F}$ was separated by centrifugation at a speed of $9000 \mathrm{rpm}$ for $30 \mathrm{~min}$. The three-phase contact angle of this fluid on the film material was measured using a customized sessile drop tensiometer. Film materials were cut each to a size of $3 \mathrm{~cm} \times 7 \mathrm{~cm}$ and glued to a microscope slide. The organic liquid was squeezed from a needle with a diameter of $0.8 \mathrm{~mm}$ onto the polymer film. The droplet shape was recorded using a Stingray F-033 camera (Allied Vision Technologies GmbH, Stadtroda, Germany), and the contact angle was obtained via image analysis program ImageJ [13].

\subsection{Spectrophotometry}

Spectrophotometry is a standard method to quantify the optical properties of materials. The transparent films were cut each to a size of $5 \mathrm{~cm} \times 5 \mathrm{~cm}$ and placed inside a spectrophotometer Lambda 950 (PerkinElmer Ltd., Llantrisant, UK). Transmission and reflection were determined in the wavelength range between $1000 \mathrm{~nm}$ and $1250 \mathrm{~nm}$. The sum of absorption, reflection, and transmission of the irradiance is equal to the total irradiance [14]. Hence, the absorption of the film materials was calculated as $100 \%$-(transmission+reflection). The absorption, transmission, and reflection of each material were compared, and the area of interest was the operating wavelength of the laser, which was $1070 \mathrm{~nm}$.

\subsection{PTP Experiment}

Electrodes from six different silver pastes (see Table 1) were fabricated using a pilot PTP machine with a maximum throughput of 3000 wafers per hour. The first squeegee blade with an angle of $60^{\circ}$ and the second squeegee blade with an angle of $130^{\circ}$ were set at a pressure of $3.5 \mathrm{~N}$ and a speed of $200 \mathrm{~mm} \cdot \mathrm{s}^{-1}$. Monocrystalline silicon precursors with a passivated emitter rear contact (PERC) structure and size of $156.75 \mathrm{~mm} \times 156.75 \mathrm{~mm}$ from a pilot line of Hanwha Q Cells (Thalheim, Germany) [15] were used as substrates and placed underneath the film at a distance of $200 \mu \mathrm{m}$. To avoid electrode interruptions, a determination of laser power threshold for each paste was performed. The laser power was increased from $300 \mathrm{~W}$ in $10 \mathrm{~W}$ steps until no interruptions could be detected on microscopy images obtained at $5 \times$ magnification, this laser power was set as the laser power threshold for the respective paste and transparent film material.

After finger metallization, all precursors were cured at $200{ }^{\circ} \mathrm{C}$ for 15 min duration using a Baccini paternoster drying oven. Then, all samples were sintered using a fast firing furnace c.FIRE (Centrotherm International AG, Blaubeuren, Germany) at a set peak temperature of $890^{\circ} \mathrm{C}$ and a belt speed of $7 \mathrm{~m} \cdot \mathrm{min}^{-1}$. Electrode morphology was imaged at 50× magnification using a laser scanning microscopy (LSM) OLS40-SU (Olympus K.K., Tokyo, Japan). 3-D images of printed electrodes were taken and analyzed using the surface analysis software Surface Texture Analysis Premium (Digital Surf) [16] to determine the height and the width of printed electrodes. The aspect ratio was calculated as height divided by width. 


\section{Results and Discussions}

First, we focus on the effect of paste flow properties on front-side metallization of solar cell using the PTP process. The influence of the organic vehicle of the silver paste and the optical properties of the film material on the laser power threshold for the transfer process are discussed separately in the subsequent sections.

\subsection{Effect of Paste Rheology on Printed Geometry}

In this section, we compare printed electrodes using the pastes A-D and film material M3 with trench shape type 1 (see Figure 3). The filling of trenches worked smoothly with all these pastes, and no unfilled trenches could be seen after the filling process irrespective of the pastes rheological properties. The measured yield stress values of the investigated pastes are summarized in Table 3.

Table 3. Yield stress of four silver pastes modified for PTP.

\begin{tabular}{cc}
\hline Paste & Measured Yield Stress at $20^{\circ} \mathbf{C}[\mathrm{Pa}]$ \\
\hline A & $204 \pm 13$ \\
B & $1025 \pm 141$ \\
C & $1130 \pm 110$ \\
D & $1623 \pm 55$ \\
\hline
\end{tabular}

Figure $4 a, b$ show that the average finger height increased and the finger width decreased with increasing yield stress. Accordingly, the aspect ratio significantly improved with increasing yield stress, as can be seen from Figure 4c. Paste A with the lowest yield stress of $204 \mathrm{~Pa}$ resulted in the smallest aspect ratio of 0.27 , and the highest aspect ratio of 0.43 was obtained using paste $\mathrm{D}$ with a yield stress of $1623 \mathrm{~Pa}$. The theoretical aspect ratio value accessible using trench 1 is 0.67 . We assume that the lower aspect ratios achieved experimentally were caused by paste spreading after deposition. To enable this, the impact pressure during paste deposition needs to be higher than the yield stress of the paste. The pressure imposed on the silver line when dropped from the film trench to the wafer is given as $\Delta p=\rho_{\text {paste }} g \cdot h$, where $\rho_{\text {paste }}=5700 \mathrm{~kg} \cdot \mathrm{m}^{-3}$ is the paste density, $g=9.81 \mathrm{~m} \cdot \mathrm{s}^{-2}$ is the acceleration due to gravity, and $h=200 \mu \mathrm{m}$ is the separation between the film and the wafer. The value $\Delta p=11 \mathrm{~Pa}$ is well below the yield stress value even of paste A obtained at $20^{\circ} \mathrm{C}$. However, two additional aspects causing the line spreading have to be considered. First, laser power dissipation results in the vaporization of volatile paste ingredients, and the corresponding gas pressure exceeding the adhesion between paste and polymer film accelerates the paste towards the substrate and provides an additional contribution to the pressure that acts on the silver paste during deposition. Second, part of the laser energy is dissipated within the silver paste and leads to an increase in paste temperature. Accordingly, the yield stress of the paste decreases. We characterized the temperature dependence of the PTP paste yield stress in the temperature range up to $40^{\circ} \mathrm{C}$, and we observed a linear decay with a drop of the yield stress of about $25 \mathrm{~Pa} /{ }^{\circ} \mathrm{C}$ [8]. Using this earlier result, we tried to estimate the paste temperature for a yield stress drop below $\Delta p$. For paste $\mathrm{A}$, the yield stress drops below $\Delta p$ around $27^{\circ} \mathrm{C}$. For pastes $\mathrm{B}, \mathrm{C}$ and $\mathrm{D}$, this limit is reached at 60,65 , and $84^{\circ} \mathrm{C}$, respectively, assuming the linear decrease to persist even at a higher temperature (see Figure A1). Both phenomena are assumed to contribute to the observed spreading of the deposited lines on the solar cell. However, further experiments would be required to quantify which of the mechanisms is more relevant for the line spreading. 

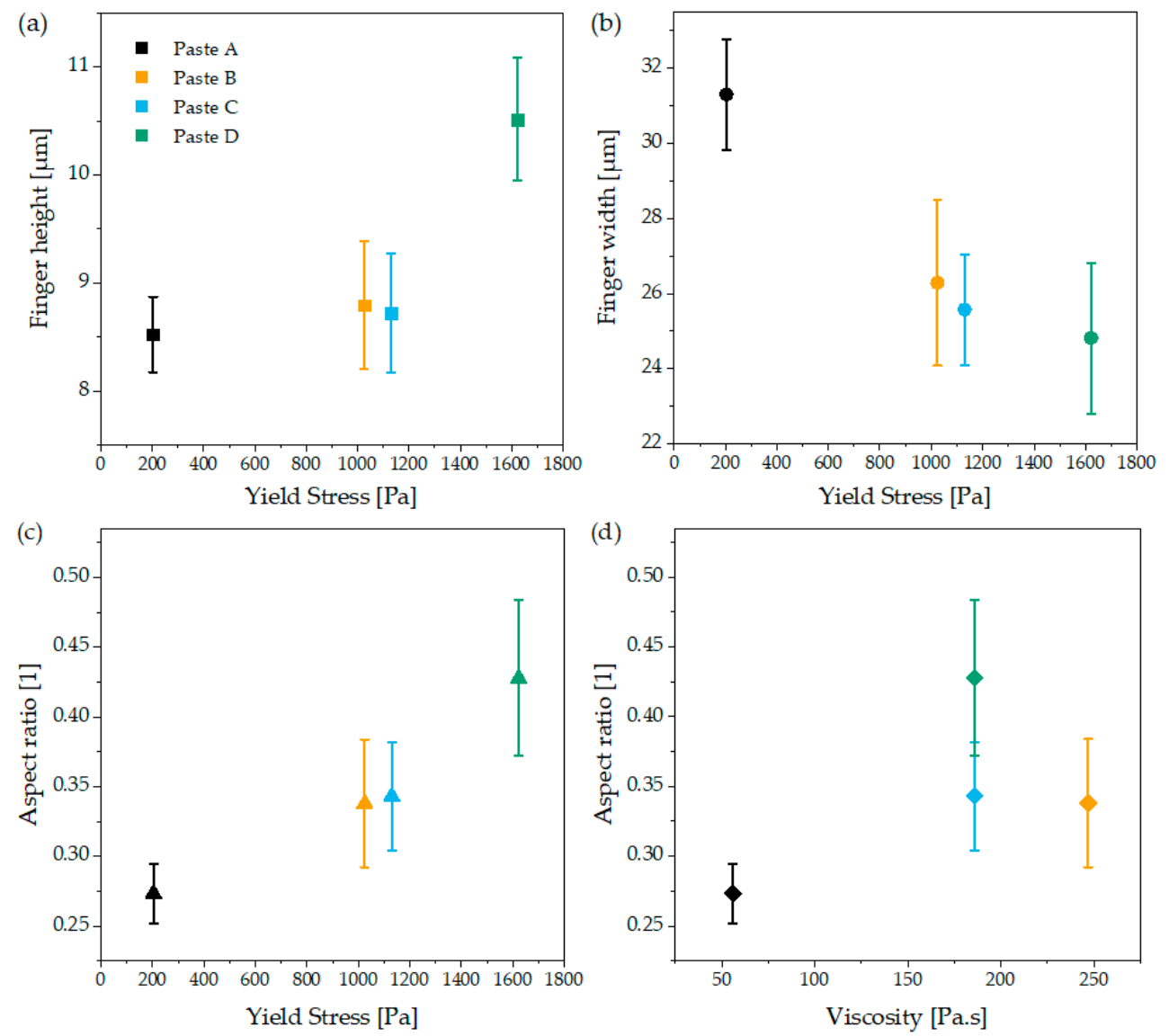

Figure 4. Geometries of electrodes obtained with pastes A-D and film material M3 with trench shape type 1: (a) finger height; (b) finger width; (c) aspect ratio vs. yield stress; (d) aspect ratio vs. viscosity.

Although we cannot quantify the true pressure that acts on the deposited line and the resistance of the paste against deformation, our results indicate that the accessible aspect ratio of silver lines printed using PTP technology is related to the paste rheology, particularly to its yield stress. The paste viscosity, in contrast, seems not to correlate to the achieved aspect ratio, as can be seen in Figure $4 \mathrm{~d}$. It should be mentioned that the viscosity was shown to be a decisive parameter for a proper paste transfer through the screen mesh in screen-printing technology [17-20]. Our results indicate that the theoretical aspect ratio of 0.67 for trench 1 might be reached for a paste with higher yield stress or weaker dependence of yield stress on the temperature. An excessively high yield stress might, however, deteriorate trench filling, and further investigations are necessary to resolve this issue.

\subsection{Influence of Organic Materials of Silver Paste on Laser Power Threshold}

Figure 5 compares the laser power threshold required to release pastes $\mathrm{E}$ and $\mathrm{F}$ from the different film materials with embossed trenches of type 2 and 3. Trench 2 demanded a higher laser power threshold than trench 3 for both pastes. We attribute this to the higher surface to volume ratio of trench 2; for this trench the ratio of circumference to equivalent horizontal interface area is 3.88 compared to 3.32 for trench 3 [8]. 


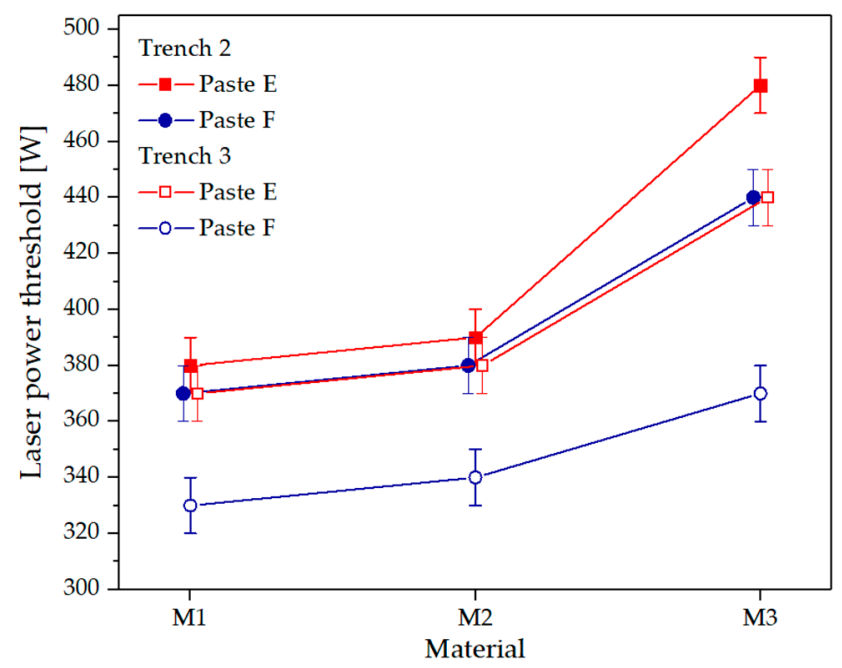

Figure 5. Nominal laser power threshold required to release pastes E and F from different film materials with trenches 2 (closed symbols) and 3 (open symbols).

Paste E required a higher laser power to release the paste entirely out of the trenches than paste F, irrespective of the tape film material. This is related to the difference in boiling temperature as well as the diverse wetting of the film material of these two pastes. As described above, a certain amount of pressure at the interface is necessary to overcome the adhesion between paste and film material. The adhesive strength is correlated to the wetting properties of the liquid organic paste components. The contact angle data shown in Figure 6a reveal that paste E wetted all three materials better than paste F. Hence, paste $\mathrm{E}$ had a stronger adhesion to all film materials than paste $\mathrm{F}$ and therefore a higher laser power threshold was required to release this paste.
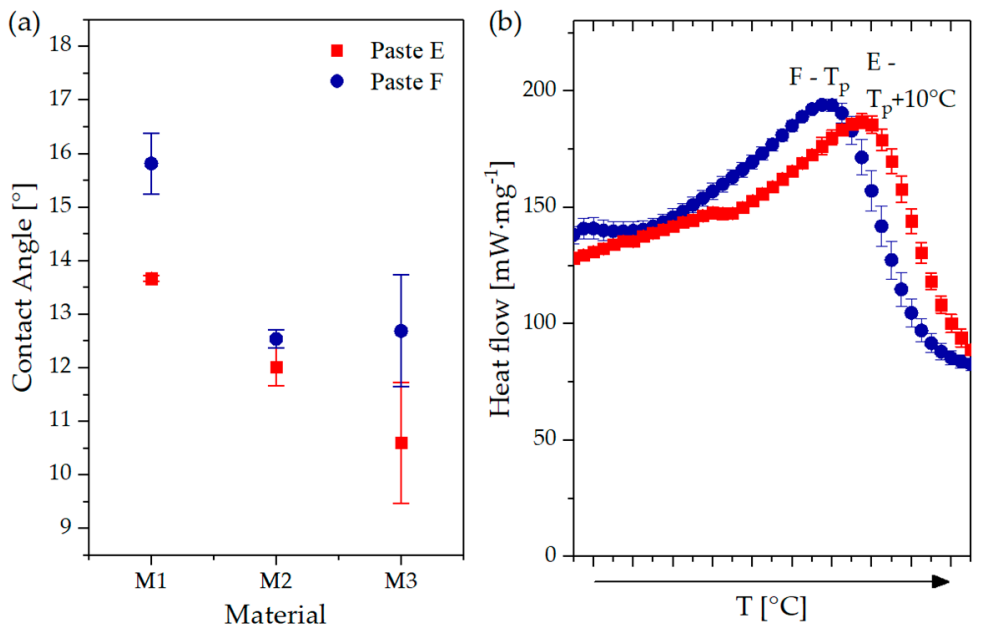

Figure 6. Influence of organic vehicles of pastes $\mathrm{E}$ and $\mathrm{F}$ on laser power threshold: (a) contact angle of organic vehicle of pastes $\mathrm{E}$ and $\mathrm{F}$ on different film materials, (b) heat flow vs. temperature for pastes $\mathrm{E}$ and $\mathrm{F}$.

Another reason for a higher laser power threshold of paste $\mathrm{E}$ compared to paste $\mathrm{F}$ is the difference in boiling temperature between these pastes. The heat flow data shown in Figure $6 \mathrm{~b}$ shows that the peak attributed to the vaporization of the volatile vehicle components occurred at $10{ }^{\circ} \mathrm{C}$ lower temperature for paste $\mathrm{F}$ than for paste $\mathrm{E}$, and accordingly the latter demands a higher laser power threshold for the PTP transfer process. However, it should be noted that the observed differences were small, and further investigations including pastes with a broader range of contact angles and boiling points might be helpful 
to corroborate our findings and to separate the contributions of wetting and boiling point differences.

\subsection{Influence of Transparent Film Material on Laser Power Threshold}

As shown in Figure 6a, the tapes are differently wetted by the pastes, and hence the tape film material significantly influences the laser power threshold. In this section, we discuss how optical properties of the polymer films contribute to the differences observed in the laser power threshold. The optical properties of the three polymer film materials are listed in Table 4. Here, the absorption was defined as the reduction of the laser irradiance that was due to the material itself. Material M1 with the lowest thickness of $80 \mu \mathrm{m}$ absorbed the $0.7 \%$ laser irradiance at wavelength $1070 \mathrm{~nm}$. Materials M2 and M3 have a similar absorption of around $0.4 \%$. Although films M2 and M3 are thicker, their absorption is lower than material M1. The low absolute absorption values and the small differences among the films indicate that the impact of light absorption on the laser power threshold is neglectable.

Table 4. Optical properties of all materials at the PTP working wavelength of $1070 \mathrm{~nm}$.

\begin{tabular}{ccccc}
\hline $\begin{array}{c}\text { Transparent } \\
\text { Film }\end{array}$ & $\begin{array}{c}\text { Film Thickness } \\
{[\boldsymbol{\mu m}]}\end{array}$ & $\begin{array}{c}\text { Absorption } \\
{[\%]}\end{array}$ & $\begin{array}{c}\text { Reflection } \\
{[\%]}\end{array}$ & $\begin{array}{c}\text { Transmission } \\
{[\%]}\end{array}$ \\
\hline M1 & 80 & $0.69 \pm 0.03$ & $10.63 \pm 0.06$ & $88.68 \pm 0.07$ \\
M2 & 150 & $0.43 \pm 0.04$ & $9.36 \pm 0.03$ & $90.21 \pm 0.02$ \\
M3 & 200 & $0.45 \pm 0.02$ & $10.01 \pm 0.01$ & $89.54 \pm 0.03$ \\
\hline
\end{tabular}

Material M2 had the best optical properties with a transmission value of $90.21 \%$ and a reflection value of $9.36 \%$ at a wavelength of $1070 \mathrm{~nm}$, followed by material M3 with a transmission of $89.54 \%$ and a reflection of $10.01 \%$, and finally M1 with $88.68 \%$ transmission and $10.63 \%$ reflection. These data show that a significant amount of laser irradiance was reflected due to surface roughness, only a small part of laser irradiance was absorbed by the polymer film, and the major fraction of incident laser irradiance was transmitted to the paste/film interface. Accordingly, the actual incident laser power at this interface was lower than the nominal laser power, which we set to the PTP machine for the printing experiment. We corrected this incident laser power with the transmission of the respective film to obtain the real laser power that induces paste release.

Figure 7 shows the comparison between the nominal and corrected laser power threshold at the paste/film interface. For both pastes, E and F, as well as for both trench shapes, trench 2 and trench 3, the material M1 with a thickness of $80 \mu \mathrm{m}$ still had the lowest laser power threshold, a slightly higher value was found for material M2 with a thickness of $150 \mu \mathrm{m}$, and the by far highest laser power threshold was observed for M3 with a thickness of $200 \mu \mathrm{m}$. Our results indicate that the laser power threshold was mainly defined by the thickness of film material. The minor differences in light transmission do not change the clear correlation that material $\mathrm{M} 1$ with the lowest transmission still requires the lowest laser power for paste release compared to M2 and M3. This result seems to be counterintuitive, but it should be kept in mind that the paste/film interface was shifted along the axis of the laser beam according to the material thickness and it might not perfectly match the laser focal plane for all films. This seems to have an effect on the laser power threshold and further investigations are necessary using films of similar thickness but made from different materials to resolve this issue. The various wetting properties of the film material of these two pastes could also play a certain role, as the lower adhesion between films and both pastes exhibited a lower laser power threshold (see Figure A2). 



Figure 7. Comparison of nominal and corrected laser power threshold of pastes $\mathrm{E}$ and $\mathrm{F}$ for trench 2 (left) and trench 3 (right).

\section{Conclusions}

As the two main aspects of the PTP transfer process from a materials point of view, the influence of paste rheology and film materials on PTP application for metallization of solar cells were investigated in this study. The aspect ratio of PTP-printed electrodes clearly improved with increasing paste yield stress but did not correlate to its viscosity. A high paste yield stress was necessary to minimize line spreading after paste release caused by additional pressure that was due to the vaporization of paste vehicle components and the decrease yield stress that was due to localized heating at the paste surface. Furthermore, we observed that a low laser power threshold for paste release could be achieved through a low boiling point of the paste organic vehicle and low wettability between the paste and film. The film materials investigated exhibited only small differences regarding absorption, reflection, or transmission of incident laser irradiance.

The present study establishes the basis and provides guidelines for future research on designing the pastes and modifying the film materials for PTP-based solar cell metallization. Finally, narrower electrodes with higher aspect ratio could be achieved using the PTP technology at even lower laser power threshold when the paste yield stress and the wetting between paste and film were adapted carefully.

Author Contributions: Conceptualization, A.A. and N.W.; methodology, A.A. and N.W.; investigation, A.A.; writing-original draft preparation, A.A.; writing-review and editing, A.A., D.R., J.L. and N.W.; visualization, A.A.; supervision, J.L. and N.W.; project administration, D.R. and J.L.; funding acquisition, D.R., J.L. and N.W. All authors have read and agreed to the published version of the manuscript.

Funding: This research was funded by the German Federal Ministry for Economic Affairs and Energy (BMWi) under the Refined PV Project (FKZ 0324206).

Institutional Review Board Statement: Not applicable.

Informed Consent Statement: Not applicable.

Data Availability Statement: Data is contained within the article.

Acknowledgments: The authors wish to thank Hanwha Q Cells GmbH for the preparation of precursors in this study and Heraeus Precious Metals for supplying tailored paste for PTP application. We acknowledge support by the KIT-Publication Fund of the Karlsruhe Institute of Technology.

Conflicts of Interest: The authors declare no conflict of interest. 


\section{Appendix A}

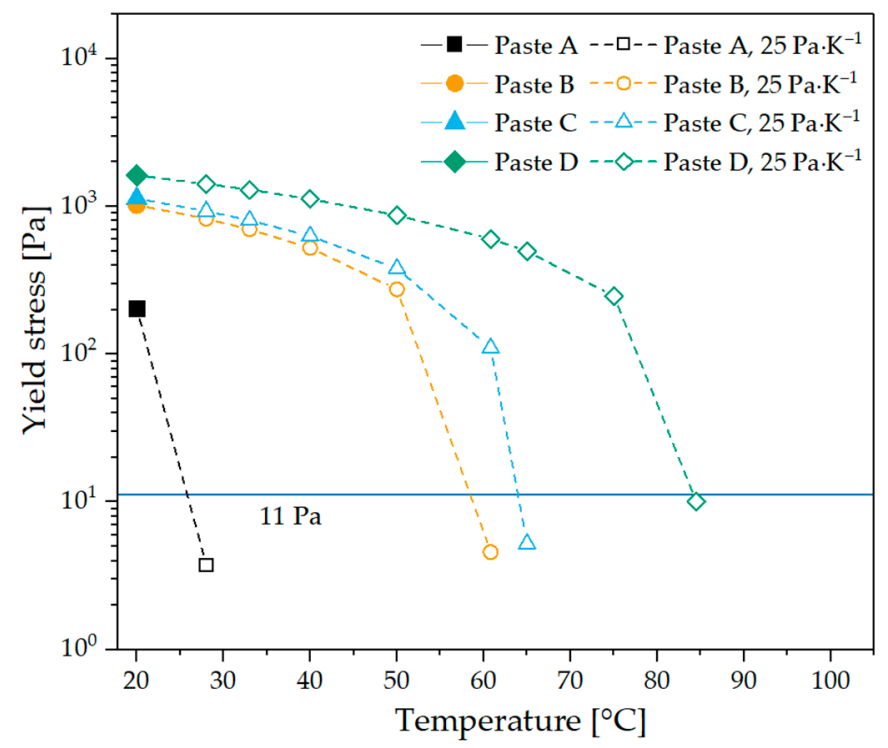

Figure A1. Yield stress versus temperature for pastes A-D. Values for temperatures $>20^{\circ} \mathrm{C}$ (open symbols) have been extrapolated assuming a linear decay with $25 \mathrm{~Pa} \cdot \mathrm{K}^{-1}$. The horizontal line at $11 \mathrm{~Pa}$ is the gravitational pressure imposed on the silver line during the PTP laser transfer process onto the substrate with a distance of $200 \mu \mathrm{m}$

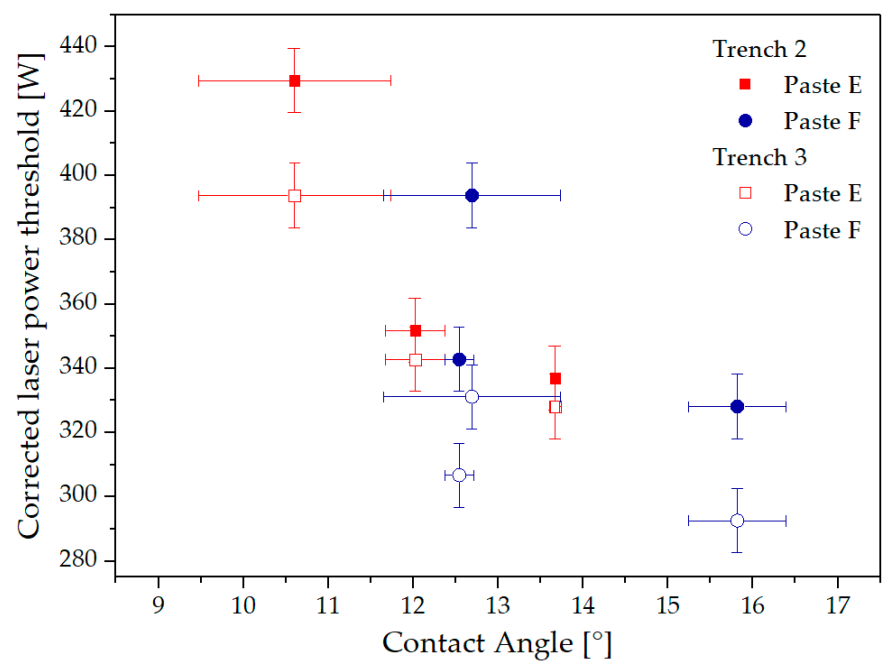

Figure A2. Corrected laser power threshold versus contact angle for pastes E (red squares) and F (blue circles), as well as trenches type 2 (closed symbols) and type 3 (open symbols).

\section{References}

1. Sharma, V.; Aziz, S.M.; Haque, M.H.; Kauschke, T. Effects of high solar photovoltaic penetration on distribution feeders and the economic impact. Renew. Sustain. Energy Rev. 2020, 131, 110021. [CrossRef]

2. International Energy Agency. Renewables Information: Overview. IEA, Paris, France. 2020. Available online: https://www.iea. org/reports/renewables-information-overview (accessed on 6 October 2020).

3. VDMA Photovoltaic Equipment. International Technology Roadmap for Photovoltaic (ITRPV)—2019 Results, 11th ed., 2020, Frankfurt, Germany. Available online: https:/ /itrpv.vdma.org/download (accessed on 30 September 2020).

4. $\quad$ Clement, F.; Linse, M.; Tepner, S.; Wengenmeyr, N.; Ney, L.; Krieg, K.; Lorenz, A.; Pospischil, M.; Bechmann, S.; Oehrle, K.; et al. "Project FINALE" - Screen and screen printing process development for ultra-fine-line contacts below $20 \mu \mathrm{m}$ finger width. In Proceedings of the 36th European Photovoltaic Solar Energy Conference and Exhibition, Marseille, France, 9-13 September 2019; pp. 259-262. [CrossRef] 
5. Tepner, S.; Ney, L.; Linse, M.; Lorenz, A.; Pospischil, M.; Masuri, K.; Clement, F. Screen pattern simulation for an improved front-side Ag-electrode metallization of Si-solar cells. Prog. Photovolt. Res. Appl. 2020, 28, 1054-1062. [CrossRef]

6. Lossen, J.; Matusovsky, M.; Noy, A.; Maier, C.; Bähr, M. Pattern transfer printing (PTP ${ }^{\mathrm{TM}}$ ) for C-Si solar cell metallization. In Energy Procedia; Elsevier Ltd.: Amsterdam, The Netherlands, 2015; Volume 67, pp. 156-162. [CrossRef]

7. Adrian, A.; Rudolph, D.; Lossen, J.; Matusovsky, M.; Chandrasekaran, V. Benefits of pattern transfer printing method for finger metallization on silicon solar cells. In Proceedings of the 35th European Photovoltaic Solar Energy Conference and Exhibition, Brussels, Belgium, 24-27 September 2018; pp. 434-438. [CrossRef]

8. Adrian, A.; Rudolph, D.; Willenbacher, N.; Lossen, J. Finger metallization using pattern transfer printing technology for C-Si solar cell. IEEE J. Photovolt. 2020, 10, 1290-1298. [CrossRef]

9. De Rose, R.; Malomo, A.; Magnone, P.; Crupi, F.; Cellere, G.; Martire, M.; Tonini, D.; Sangiorgi, E. A methodology to account for the finger interruptions in solar cell performance. Microelectron. Reliab. 2012, 52, 2500-2503. [CrossRef]

10. Lossen, J.; Rudolf, D.; Adrian, A.; Koduvelikulathu, L. How many finger-interruptions should we tolerate? In Proceedings of the Metallization \& Interconnection Workshop 2019, Konstanz, Germany, 13-14 May 2019.

11. Dzuy, N.Q.; Boger, D.V. Yield stress measurement for concentrated suspensions. J. Rheol. 1983, 27, 321-349. [CrossRef]

12. Yüce, C.; Willenbacher, N. Challenges in rheological characterization of highly concentrated suspensions-a case study for screen-printing silver pastes. J. Vis. Exp. 2017, 2017, e55377. [CrossRef]

13. Schneider, C.A.; Rasband, W.S.; Eliceiri, K.W. NIH image to ImageJ: 25 years of image analysis. Nat. Methods. 2012, 9, 671-675. [CrossRef] [PubMed]

14. Bass, M. Handbook of Optics, Volume II-Devices, Measurements, and Properties, 2nd ed.; McGraw-Hill, Inc.: New York, NY, USA, 1995; ISBN 0-07-047974-7.

15. Lee, B.G.; Schaper, M.; Bakowskie, R.; Bus, D.; Won, R.; Muller, J.W.; Cieslak, J.; Schwabedissen, A.; Wissen, D.; Geisler, S.; et al. Development and mass production of bifacial Q.ANTUM p-Cz PERC cells. In Proceedings of the IEEE 46th Photovoltaic Specialists Conference (PVSC), Chicago, IL, USA, 16-21 June 2019; pp. 1460-1462. [CrossRef]

16. MountainsMap Surface Texture Analysis Premium; Version. 5.1.0.5338; Digital Surf: Besançon, France, 2009.

17. Zhou, Y.; Tong, H.; Liu, Y.; Yuan, S.; Yuan, X.; Liu, C.; Zhang, Y.; Chen, G.; Yang, Y. Rheological effect on screen-printed morphology of thick film silver paste metallization. J. Mater. Sci. Mater. Electron. 2017, 28, 5548-5553. [CrossRef]

18. $\mathrm{Xu}, \mathrm{C}$; W Willenbacher, N. How rheological properties affect fine-line screen printing of pastes: A combined rheological and high-speed video imaging study. J. Coat. Technol. Res. 2018, 15, 1401-1412. [CrossRef]

19. Hoornstra, J.; Weeber, A.W.; de Moor, H.; Wim, S. The importance of paste rheology in improving fine line, thick film screen printing of front side metallization. In Proceedings of the 14th European Photovoltaic Solar Energy Conference, Barcelona, Spain, 30 June-4 July 1997; pp. 823-826, ISBN 1-901675-01-09.

20. Tepner, S.; Wengenmeyr, N.; Linse, M.; Lorenz, A.; Pospischil, M.; Clement, F. The link between ag-paste rheology and screenprinted solar cell metallization. Adv. Mater. Technol. 2020, 5, 2000654. [CrossRef] 